\title{
Effect of Interactive Teaching Methods on Removable Partial Denture Designing
}

\author{
Hina Zafar Raja ${ }^{1}$ \\ Maryam Mumtaz ${ }^{2}$ \\ Ambreen Shabbir ${ }^{3}$ \\ Muhammad Nasir Saleem ${ }^{4}$
}

Asma Shakoor ${ }^{5}$

\author{
BDS, FCPS, MSc \\ BDS \\ BDS, M.Phil, MHPE \\ BDS, FCPS, MSc \\ BDS, MSc, MFDSRCS(Ed)
}

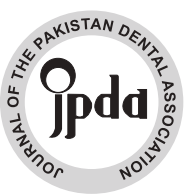

OBJECTIVE: The aims of this study were to, (a) Assess the level of skill acquired for designing removable partial dentures through two teaching methods individually, on two courses of dental graduates. (b) Compare the level of skill of dental graduates acquired through two teaching methods for designing removable partial dentures for diverse clinical situations. Materials and METHODOLOGY: This quasi-experimental study comprised of application of two interactive teaching methods over two courses of Dental students over a period of three years. Course I, $(n=113)$ was assessed with a brainstorming session without a prior formal lecture. Course II $(n=102)$ was exposed to an interactive lecture followed by a formative assessment of RPD deigning. Each participant was asked to design a removable partial denture for a clinical scenario. Assessment was based on specific satisfaction criteria. Data was analyzed descriptively and compared with student's t test.

RESULTS: Out of all participants, $70 \%$ of participants in course I and $63 \%$ percent from course II showed partial satisfaction. 8-15\% were able to achieve complete satisfactory scores. On comparison of two courses, mean total score in course I was $3.31 \pm 1.21$ and in course II mean total score was $3 \pm 1.30$, thus, p-value was 0.072 , which was statistically insignificant. CONCLUSION: The level of skill acquired for designing a removable partial denture through two interactive teaching methods was only partially satisfactory for most participants of both courses. The level of skill acquired from brainstorming was comparable to the skill acquired from an interactive lecture. The difference of assessment scores in both scenarios was not statistically significant.

KEYWORDS: Denture, Partial, Removable; Learning; Problem solving; Curriculum; Universities; Schools, Dental.

HOW TO CITE: Raja HZ, Mumtaz M, Shabbir A, Saleem MN, Shakoor A. Effect of interactive teaching methods on removable partial denture designing. J Pak Dent Assoc 2020;29(3):124-129.

DOI: https://doi.org/10.25301/JPDA.293.124

Received: 13 June 2020, Accepted: 17 June 2020

\section{INTRODUCTION}

A well planned removable partial denture (RPD) restores oral functions, esthetics and imparts minimum stress to the hard and soft tissues of oral cavity. ${ }^{1}$ Poorly designed removable partial dentures may result in periodontal bone loss, caries, gingivitis, periodontal damage and stomatitis of supporting tissues. ${ }^{2,3,4}$ Acquisition

1. Professor, Department of Prosthodontics, Institute of Dentistry, CMH Lahore Medical College, Lahore, Pakistan.

2. Resident, Department of Prosthodontics, Institute of Dentistry, CMH Lahore Medical College, Lahore, Pakistan.

3. Associate Professor, Department of Pathology, CIMS, Pakistan.

4. Professor, Department of Operative Dentistry, Institute of Dentistry, CMH Lahore Medical College, Lahore, Pakistan.

5. Associate Professor, Department of Community \& Preventive, Institute of Dentistry, CMH Lahore Medical College, Lahore, Pakistan.

Corresponding author: "Dr. Hina Zafar Raja" < hinazafarraja@gmail.com > of skill of partial denture design is crucial to its successful implementation during clinical practice. ${ }^{1}$ Many designs proposed in literature are without sufficient scientific evidence. ${ }^{5}$ Worldwide studies have shown disagreements over removable partial denture designs as well as lack of communication skills of dentists, pertaining to details of removable partial denture design to dental laboratories. ${ }^{6,7}$ Although digital designing of dentures is gaining popularity, but the importance of knowledge of basic principles of denture designing cannot be negated. ${ }^{8}$ Curricula of all leading universities require attainment of partial dentures designing competency for graduating dental students. ${ }^{9}$ Contemporary under-graduate prosthodontic teaching in most dental schools comprises of a non-examinable pre-clinical skill component in early years, followed by theoretical knowledge with a practical component in 
subsequent years. Many dental schools are not following an equivalent pattern of teaching of removable partial dentures. This disparity is present at various levels of academic years i.e. second year ${ }^{10}$, third year or final year. In addition, number of credit hours spent on each component of partial dentures for theory and practical teaching, varied teacher student ratio in many dental schools, reliance of students on teaching staff for denture designing ${ }^{8}$, reliance on dental technicians for partial denture construction, limited patient exposure of dental students, inability of students to perform laboratory work of their patients and non-availability of surveyors, semi-adjustable articulators within dental schools are factors that affects the skill of budding professionals. ${ }^{11,12}$ In some institutions, reduction in practical teaching is compensated by increased dependency on audiovisual aids. This may have a negative effect on achievement of adequate manual skills. ${ }^{12}$ As partial denture designing mandates sound clinical knowledge with sufficient grip on clinical dexterity, which may not be achieved with alternate means.

A Prosthodontics student must acquire knowledge thoroughly based on scientific evidence, and apply it clinically with critical thinking. ${ }^{13}$ The gradual acquisition of knowledge and skill in dentistry improves with exposure and experience. Studies have evaluated undergraduate preclinical and final year students for teeth preparations for better adaptability of partial denture components ${ }^{14}$ and RPD designing. ${ }^{1}$ The gain of such skill is difficult to assess at preclinical years, when a student is still in a phase of acquiring basic knowledge of prosthodontics. Gradually in third year or final year levels, the interrelations of prosthodontics with other specialties like endodontics/ periodontics and skill of removable partial denture designing and construction are learnt. ${ }^{15}$ This phenomenon of gradual acquisition of skill can be explained with bloom's taxonomy. ${ }^{16}$

Globally, there is a diversity in the preferred method of teaching in different regions. In Pakistan, limited scientific evidence is available in this regard. Studies have shown significant preference for the interactive teaching methods over didactic modes of learning. ${ }^{17}$ Teaching of partial dentures can be done through conventional teaching (elaborate lectures covering basic principles of dentures design for a specific Kennedy's class). Interactive teaching is also recommended for partial denture designing. It may include individual or collective participation of all students and team based learning. ${ }^{13}$ Small group discussion and problem-solving based learning can aid in better understanding of the subject. It can be achieved through brainstorming for a clinical scenario without a prior didactic teaching or designing partial dentures as an exercise taken after an interactive lecture. ${ }^{18}$ It can be hypothesized that interactive teaching done with last two methods, may result in better outcome of dental students as compared to a brainstorming session without a prior didactic lecture than teaching done with an interactive lecture followed by a mock exercise only. Effective teachers may incorporate multiple teaching methods to improve students' competencies..$^{19,20}$

The rationale of this study was to utilize diverse interactive teaching methods for improved skill of partial denture designing of dental students. The aims of this study were to, Assess the level of skill acquired for designing removable partial dentures through two teaching methods individually, over two courses of dental graduates.

Compare the level of skill of dental graduates acquired through two teaching methods for designing removable partial dentures for diverse clinical situations.

\section{METHODOLOGY}

This quasi-experimental study was done individually over two courses of BDS from two Private Dental Colleges of Lahore, Pakistan over a period of three years, from 20162019. The study was approved by Institutional Review Board. The data obtained was kept anonymous and all principles pertaining to data protection were strictly followed. The description of courses and the teaching method utilized is as follows.

Course I: Removable Partial Denture designing using brainstorming: This course comprised of $113(n=113)$ participants. Participants had completed four years of BDS, covering 460 credit hours for Prosthodontics. They were going through their house job. For the present study, the participants were asked to design a removable partial denture through brainstorming, over a worksheet comprising of a clinical scenario, with details of health status, magnitude and location of undercuts of primary abutments of a partial denture arch classified as Kennedy's class 2 modification 1. Prior to this exercise, no formal traditional lecture was delivered. The RPD designs were evaluated for these components.

1. Rest

2. Indirect retainer

3. Retentive arm of the clasp assembly

4. Reciprocal arm of the clasp assembly

5. Minor connector

6. Major connector

Course II: Interactive lecture followed by individual brainstorming: This course comprised of $102(n=102)$ participants. The participants had completed their theoretical 
and clinical rotations in preclinical and third year, covering 135 and 150 prosthodontics credit hours respectively. At the time of study, they were going through their theoretical and clinical rotations in final year. A series of three hours of traditional lectures on basic principles of removable partial denture designing of bounded and free end saddles were held. At the end of third lecture, an interactive session on concepts of removable partial denture designing took place followed by a formative assessment on worksheets. Five different clinical situations of free end and bounded saddles were presented on different worksheets, with clinical scenarios describing magnitude and location of undercuts. Each student got only one Kennedy's classification clinical picture and was asked about class definition, outlining of saddle areas, choice of major connector, options for means of retention, and means of support on all possible abutments. Researchers made a key of all plausible options for each component, as given in reference text books. ${ }^{21,22}$ All the designs submitted by the students were evaluated and scored according to the same criteria as Course I.

The evaluation criteria utilized was taken from a previous study. ${ }^{1}$ Out of a total score of 6 , scores were classified as 'Completely appropriate' for scoring 5-6 marks, 'Partially appropriate' for scoring 3-4 marks, and 'Inappropriate' for scoring 0-2 marks. Three examiners assessed the RPD designs for each course individually. An average of their individual score was considered as a final score for that particular design. The data was entered and analyzed SPSS version 23.0. $\mathrm{p}$ value was considered significant when it will be $\leq 0.05$.

\section{RESULTS}

Descriptive and frequency analysis were done for all scores in both courses to assess the level of skill acquired for designing removable partial dentures through two teaching methods individually. Course I had 113 participants $(n=113)$. Participants were going through their house job. They had completed 460 Prosthodontics credit hours. Course

Table 1: Total Assessment Classification Percentages of all Participants of Course I $(n=113)$ and Course II $(n=102)$.

\begin{tabular}{|l|l|l|}
\hline & \multicolumn{2}{|l|}{ Groups } \\
\hline Satisfaction & Course 1 & Course 2 \\
\hline Completely satisfactory & $17(15.0 \%)$ & $11(10.8 \%)$ \\
\hline Partially satisfactory & $70(61.9 \%)$ & $63(61.8 \%)$ \\
\hline Unsatisfactory & $26(23.0 \%)$ & $28(27.5 \%)$ \\
\hline Total & $113(100.0 \%)$ & $102(100.0 \%)$ \\
\hline
\end{tabular}

II had 102 participants $(n=102)$. They had completed 285 credit hours. Out of all participants, $92.09 \%$ were in age range of 21-25 years (Figure 1).

$72 \%$ of all participants in both courses were females

Figure 1: Age distrubution of participants of Course I ( $n=113)$ and Course II $(n=102)$

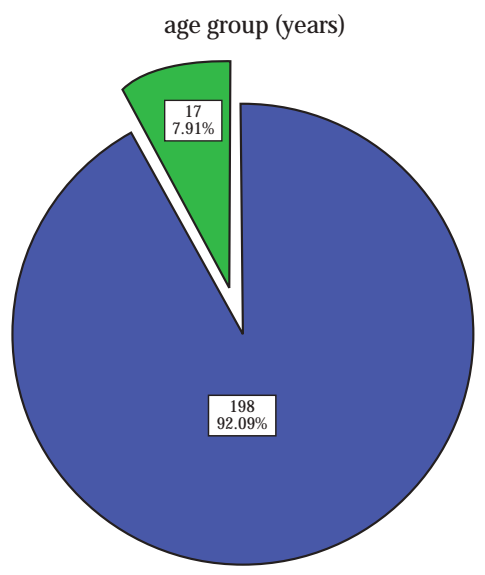

21-25 years 26-31 years

Figure 2: Gender distrubution of participants of Course I $(n=113)$ and Course II $(n=102)$

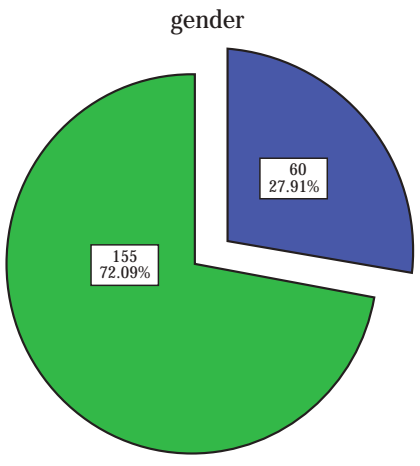

Figure 3: Mean scores obtained within Course I $(n=113)$ and Course II $(n=102)$

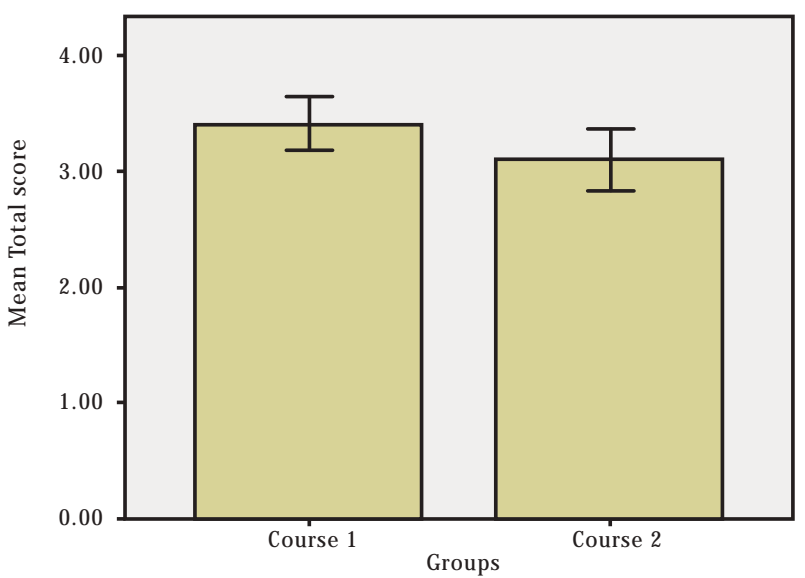


while $21 \%$ were males. (Figure 2) The scores of each participant were assessed according to the classification. ${ }^{1}$ $70 \%$ of participants in course I showed partially satisfaction, while $63 \%$ percent from course II showed the same grade. The difference in both courses was not statistically significant. (Table 1) However, only 8-15\% were able to achieve complete satisfactory scores.

The data obtained from each course in Student's t test was applied to compare the level of skill of dental graduates acquired through two teaching methods for designing removable partial dentures for diverse clinical situations. The mean total score in course I was $3.31 \pm 1.21$ and in course II the mean total score was $3 \pm 1.30$. (Figure 3 ) The mean total score in both courses was statistically same, thus, p-value was 0.072 , which was statistically insignificant.

\section{DISCUSSION}

The use of removable partial dentures is expected to increase owing to cumulative awareness towards oral health and conservation of natural structures. ${ }^{3,4}$ Since removable partial dentures are intended to be placed and removed from the mouth on a daily basis, they are subjected to move under functional forces and other biomechanical stresses. Clinicians must design each component of the partial denture to ensure favorable distribution of these stresses. ${ }^{3}$ Inadequate planning of a removable partial denture might become the most costly way to extract a tooth. A review of the researches and surveys done on this subject brings to light the fact that a fundamental problem exists pertaining to the designing and fabrication of removable partial dentures. . $^{1,10,12,13,14}$

According to the results obtained in this study, the majority of dental students had partial satisfactory skills for designing of removable partial dentures. There is a myriad of reasons for this observation. According to surveys done in dental schools in different regions of the world, a few observations common to all included a lack of practical application of the theoretical principles of partial denture design by the students. ${ }^{4}{ }^{12}$ However, the level of participants in these studies were diverse. A valid assessment requires accurate measurement of its subject. Hence, the academic level students may also affect the assessment scores of designing skills for RPD.

A removable partial denture can be an interim or definitive prosthesis. Its planning and designing requires careful understanding of all domains of dentistry, that might affect the prognosis of a possible abutment tooth. A preclinical, or third year student may not fully understand the inter relation of prosthodontics with other specialties. In the present study, the participants of both courses were either going through their vocational training (Course I) or were in final year of their training, with on going clinical rotations (Course II). This implies sufficient exposure of participants to the varied clinical scenarios as evident in other studies depicting better skills of RPD designing by house officers. ${ }^{20}$

The method of teaching at under graduate level is also a factor. In this study, instead of traditional lectures, two methods of teaching were used. One was RPD designing using brainstorming without any prior formal lecture. The second was interactive teaching session followed by a mock exam. The goal of these methods was to engage the students practically and allow them to use their own critical thinking and competency level in different clinical scenarios. According to the results obtained, there was no statistically significant difference amongst the two teaching methods (Table 1, Figure 3). According to a study conducted in the University of Florida in 2015, the traditional method of lecture based teaching is not very effective in the area of clinical knowledge. ${ }^{11}$ An improved clinical performance was observed by introducing team based learning methods in which practical involvement of students is encouraged. Multiple teaching methods have been shown to be more effective and better accepted by students as compared to the conventional lecture based, single teaching approach. ${ }^{11,12}$ Practical courses with small group discussions, problem solving exercises, interactive sessions with videos and selfdirected learning are all novel methods of teaching gaining popularity. ${ }^{10,12}$ In present study, both teaching methods for each course were interactive, which is contrary to conventional lecturing method. In addition, the method applied on first course had no recent exposure to the basic knowledge of the subjects. Despite this, the results obtained were almost similar in all courses and all scenarios. Thus the results of the study showed null hypothesis. This observation implies that the incorporation of preferred learning style of learners may help in alleviation of extrinsic load on students and augment their learning capabilities. ${ }^{23,24}$ Such interactive teaching modalities result in better performance and participation on the students' behalf as compared to the traditional lectures. . $^{111,12,13}$

In majority dental schools, students tend to depend on the teachers and technical staff to design and fabricate the partial dentures. This dependency is carried forwards in general dental practice in the form of complete reliance on dental technicians for partial denture design. This leads to a lack of expertise and skill in professional life. ${ }^{4,11}$ On the contrary, the students during their clinical rotations may be directed to organize a comprehensive treatment plan for a particular patient, instead of focusing on the denture part only. This may improve their critical thinking and refine their clinical judgement. 


\section{LIMITATIONS}

The limitation of this study was that participants in this study were assessed at different times of their courses. If all participants were at a similar academic level, it would improve the level of evidence. It is therefore recommended to pursue this research with introduction of other teaching methods for the same subjects to achieve a unanimous conclusion.

\section{CONFLICT OF INTEREST}

The authors declare that there is no conflict of interest.

\section{ACKNOWLEDGEMENTS}

We thank Dr. Asif Hanif (Director Biostatistics UnitFaculty of Allied Health Sciences) for helping with the statistics and reviewing this article.

This study was not funded by any organization or institute.

\section{CONCLUSIONS}

The following conclusions were observed from this study.

1. The level of skill acquired for designing a removable partial denture through two interactive teaching methods was partially satisfactory in most participants of both courses (63\%-70\%). However, only 8-15\% were able to achieve complete satisfactory scores.

2. The level of skill acquired from brainstorming was comparable to the skill acquired from an interactive lecture. The difference of assessment scores in both scenarios was not statistically significant. The study showed null hypothesis. 3. Globally, there is a dire need for improvement of teaching methodologies pertaining to removable partial dentures planning and designing.

\section{REFERENCES}

1. Neto AF, Duarte ARC, Shiratori FK, Leite PHdAeS, RizzattiBarbosa CM, Bonachela WC. Evaluation of Senior Brazilian Dental Students About Mouth Preparation and Removable Partial Denture Design. J Dent Educ. 2010;74:1255-60.

https://doi.org/10.1002/j.0022-0337.2010.74.11.tb05001.x

2. Ezawi AAE GD, Taylor PD The Impact of Removable Partial Dentures on the Health of Oral Tissues: A Systematic Review. . Int J Dent Oral Health 2017;3:1-8.

https://doi.org/10.16966/2378-7090.226

3. Campbell SD, Cooper L, Craddock H, Hyde TP, Nattress B, Pavitt $\mathrm{SH}$, et al. Removable partial dentures: The clinical need for innovation.
J Prosthet Dent. 2017;118:273-80.

https://doi.org/10.1016/j.prosdent.2017.01.008

4. Myint Oo KZ, Fueki K, Yoshida-Kohno E, Hayashi Y, Inamochi Y, Wakabayashi N. Minimal clinically important differences of oral health-related quality of life after removable partial denture treatments. J Dent. 2020;92:103246.

https://doi.org/10.1016/j.jdent.2019.103246

5. Khan SB, Geerts GA. Aesthetic clasp design for removable partial dentures: a literature review. Sadj. 2005;60:190-94.

6. Lynch CD, Allen PF. A survey of chrome-cobalt RPD design in Ireland. Int J Prosthodont. 2003;16:362-64.

https://doi.org/10.1093/jdh/16.4.362-a

7. Owall B, Budtz-Jorgensen E, Davenport J, Mushimoto E, Palmqvist S, Renner R, et al. Removable partial denture design: a need to focus on hygienic principles? Int J Prosthodont. 2002;15:371-78.

8. Fayyaz M, Ghani F. Appropriateness of knowledge and practices of dentists relating to using clasps in removable partial dentures. J Ayub Med Coll Abbottabad. 2008;20:52-5.

9. Florida CoDUo. Curriculum Overview 2020 [Available from: https://dental.ufl.edu/education/dmd-program/curriculumoverview/\#year-three.

10. Loch C, Brunton PA, Rahim ZA, Liew L, Lynch CD, Wilson N, et al. The teaching of removable partial dentures in dental schools in Oceania. J Dent. 2020;95:103309.

https://doi.org/10.1016/j.jdent.2020.103309

11. Lynch CD, Allen PF. The teaching of removable partial dentures in Ireland and the United Kingdom. Br Dent J. 2007;203(8):E17. https://doi.org/10.1038/bdj.2007.581

12. Clark RK, Radford DR, Juszczyk AS. Current trends in removable partial denture teaching in British dental schools. Br Dent J. 2011;211:531-35.

https://doi.org/10.1038/sj.bdj.2011.1003

13. Echeto LF, Sposetti V, Childs G, Aguilar ML, Behar-Horenstein LS, Rueda L, et al. Evaluation of Team-Based Learning and Traditional Instruction in Teaching Removable Partial Denture Concepts. J Dent Educ. 2015;79:1040-48.

https://doi.org/10.1002/j.0022-0337.2015.79.9.tb05997.x

14. Curtis DA, Lind SL, Brear S, Finzen FC. The correlation of student performance in preclinical and clinical prosthodontic assessments. $\mathrm{J}$ Dent Educ. 2007;71:365-72.

https://doi.org/10.1002/j.0022-0337.2007.71.3.tb04286.x

15. Johnson A, Wildgoose DG. Partial denture design comparisons between inexperienced and experienced undergraduate students and the teaching staff of a UK dental school. Br Dent J. 2010;209:287-92. https://doi.org/10.1038/sj.bdj.2010.817

16. Krathwohl DR, Anderson LW. A taxonomy for learning, teaching, 
and assessing: A revision of Bloom's taxonomy of educational objectives: Longman; 2009.

17. Alaagib NA, Musa OA, Saeed AM. Comparison of the effectiveness of lectures based on problems and traditional lectures in physiology teaching in Sudan. BMC Medi Educ. 2019;19:365.

https://doi.org/10.1186/s12909-019-1799-0

18. Abdulhadi Al-Samawi L, Mohammed H, editors. Multiple teaching methods to enhance removable partial learning outcome and designing skill for undergraduate dental students. a personal experience. Proceedings of INTED2014 Conference; 2014 10th-12th March; Valencia, Spain.

19. Khalid A RK, Bashir Z, Hanif A. Learning style preferences among students of Shalamar Medical and Dental College, Pakistan. Adv Health Prof Educ. 2015;1:13-7.

20. Anthony L, Latt S, Afrose T, Khaing I. Preferred Teaching Methods by Medical and Dental Students of a Private University: The Students' Perception. 2018; Volume 6:106-11.

21. Carr AB. Mccracken's removable partial prosthodontics. St. louis: Elsevier mosby; 2016.

22. Davenport JC, British Dental A. A clinical guide to removable partial denture design. London: British Dental Association; 2007.

23. Hernandez-Torrano D, Ali S, Chan CK. First year medical students' learning style preferences and their correlation with performance in different subjects within the medical course. BMC Med Educ. 2017; 17:131.

https://doi.org/10.1186/s12909-017-0965-5

24. Young JQ, Van Merrienboer J, Durning S, Ten Cate O. Cognitive Load Theory: implications for medical education: AMEE Guide No. 86. Med Teach. 2014;36:371-84.

https://doi.org/10.3109/0142159X.2014.889290 